\title{
Questão prática, resposta CRíticA o metateatro de Sabina Berman
}

\author{
Alessandra Dutra dos Santos \\ UFMG
}

\begin{abstract}
RESUMO
Este artigo visa discutir os conflitos existentes entre teoria e prática teatral, utilizando como instrumentos dois monólogos da dramaturga mexicana Sabina Berman e o manual de preparação do ator de Stanislavski, buscando resgatar o diálogo existente entre os dois textos.
\end{abstract}

\section{PALAVRAS - CHAVE}

teoria teatral, Sabina Berman, Stanislavski

$\mathbf{E}_{\text {ste trabalho tem como objetivo analisar uma pequena parte da obra de Sabina }}$ Berman, dramaturga mexicana, procurando enfatizar os principais pontos que marcam a escrita desta autora. Para isto foi selecionado um monólogo de 1975, chamado Esta no es una obra de teatro, que se desdobrou numa segunda versão intitulada Un actor se repara, de 1984. Porém a abordagem que será feita desta escrita visa discutir os conflitos existentes entre teoria e prática teatral que sāo apresentados por Sabina, de forma exemplar, dentro dos próprios monólogos. Esclareço que as duas versões do monólogo serão discutidas conjuntamente, pois julgo tratar-se de uma composição única, embora haja alguns acréscimos e omissões na segunda versão.

\section{O TEXTO}

Esta no es una obra de teatro foi escrita exclusivamente para ser lida e sua reescrita, Un actor se repara, com um formato mais dramático e menos anedótico, para ser encenada. Sobre o monólogo, vale ressaltar que é um tipo de texto que foi utilizado por autores inclinados à introspecção, nos séculos XVIII e XIX, principalmente na França. O teatro clássico francês, apegado à verossimilhança, aceitou-o sem restrições. Segundo alguns estudiosos de teatro, o monólogo é freqüentemente utilizado em momentos em que o personagem apresenta uma incipiente desagregação mental.

Sabina Berman nos apresenta a história de um candidato a ator em seu exame de audição. À primeira vista, o assunto parece banal. Porém, a maneira como Sabina se debruça sobre o tema garante-lhe consistência e atualidade. Sabina Berman foi testemunha ocular da história que nos narra e transpõe para o papel não o relato de como tudo realmente aconteceu, mas de como foi visto e interpretado por ela, estando esta interpretação sujeita aos devaneios e elipses próprios da memória. Como ela mesma afirma: "La que sigue no pretende ser una rememoración exacta, apenas tan aproximada a lo que sucedió como puede ser una rememoración. La memoria, ya se 
sabe, quita, añade, transtoca: inventa." ${ }^{1}$ Neste monólogo Sabina deixa transparecer a escrita feita no calor dos acontecimentos, carregada de ações e reações que somente os momentos de clímax de uma determinada situação podem provocar.

Em Un actor se repara, Sabina nos oferece uma reescrita de Esta no es una obra de teatro, "(...) más apta para la representación escénica, menos anecdótica, formada como unidad." A peça $U n$ actor se repara conserva quase que em sua totalidade as mesmas características de Esta no es una obra de teatro. Porém em sua estrutura apresenta um número maior de interrupções na fala do personagem. Há mais pausas para o ator e mais didascálias para o encenador. No entanto, se comparada com outros autores, Sabina utiliza pouco este recurso teatral de condução da encenação, demonstrando a liberdade que sua escrita dá ao diretor e a importância que atribui às palavras pronunciadas pelo ator, mais que a qualquer sistema de desempenho. O ritmo do monólogo é rápido e as palavras parecem "vomitadas" da boca do protagonista. No cenário já não há mais a presença dos cilindros que simulavam troncos de árvores. A cena encontra-se completamente vazia, com exceção da luz que se transforma em coadjuvante do ator ou atriz, remetendo-nos ao cenário grotowskiano, o que possibilita a Sabina introduzir na nova versão do texto uma fala como esta: "Me remetes a un escenario absolutamente desamparado. Eso se llama técnicamente sadismo." ${ }^{3}$ Nesta segunda versão, Félix, protagonista da história, discute menos anedoticamente a situação do ator. $\mathrm{O}$ monólogo mantém o mesmo ritmo, força e integridade, mas inova na seriedade com que o assunto é tratado na nova versão. Isto porque, como salienta Sabina no próprio título, esta no es una obra de teatro, mas se converte em uma na segunda versão. Sabina joga com o lúdico teatral propondo aos praticantes e estudiosos de teatro um questionamento da arte teatral e, principalmente, de si próprios. A crítica da teoria não se restringe aos valores meramente conceituais, mas extrapola os limites da conceituação abarcando os valores culturais, psicológicos, políticos e sociais. Sabina lança um novo olhar sobre as teorias, transformando um simples testemunho numa obra rica, que acende em seus leitores/espectadores uma luz e procura despertar neles uma nova maneira de abordar o relacionamento entre teoria e prática teatral.

Félix, protagonista desta história, coloca o teatro e seus elementos constitutivos no banco dos réus. Na ausência de todas as teorias e teóricos, descarrega sobre o diretor, representante mais próximo destes elementos, toda a sua carga explosiva formada por dúvidas, decepções e anseios, travando uma batalha tripla: a primeira de ordem temporal - os cânones teatrais do passado entram em conflito com sua situação presente, resultando num futuro incerto, cheio de dúvidas e perguntas sem resposta; a segunda de ordem espacial - Félix busca seu espaço dentro e fora do teatro; e a terceira de ordem física/psicológica, num conflito permanente consigo mesmo.

\footnotetext{
${ }^{1}$ Berman. Esta no es una obra de teatro, p.305.

${ }^{2}$ IBIDEM. p.301.

${ }^{3}$ BERMAN. Un actor se repara, p.315. Se a presença de um cenário ajuda a melhorar a compreensão do espectador, tornando mais verossímil o que está sendo visto, a ausência deste componente da cena faz com que toda a responsabilidade pela boa compreensão da peça recaia sobre o ator, cabendo a ele atuar de maneira verossímil para que sua ação no palco nāo pareça gratuita e estereotipada, levando o espectador a repugná-lo. O personagem de Sabina se sente tão incomodado com o vazio no qual o palco se encontra que expressa verbalmente seu desconforto.
} 
Félix não nos faz uma conferência nem tampouco somos seus confidentes, mas a ocasiāo nos faz cúmplices de seu jogo dramático, de seu ato de vida ou morte no qual sua audição se transforma. Félix confiou cegamente nas teorias e procurou segui-las religiosamente, julgando-se preparado, da melhor maneira possível, para o exercício de sua profissão. As teorias, o cânone, em sua prova de fogo, demonstram ser tão frágeis quanto o próprio Félix. Porém o monólogo de Sabina não se converte em mero desabafo para o público ou em uma sessão de análise, mas constitui-se numa ampla reflexão sobre a própria condição de ser ator/atriz, desde sua formação, e da permanência e sobrevivência do fazer teatral que é aqui questionado de forma rígida e segura.

O monólogo de Sabina apresenta uma temática que vai do universal ao particular. Se todos os atores/atrizes se unem mediante a existência de um sentimento comum, a angústia e ansiedade provocadas pela audição, Sabina se dirige especialmente ao público latino-americano, quando coloca em xeque a supremacia das teorias teatrais européias.

Guiada pelas asas da memória, Sabina nos oferece uma recriação de Félix, que já não é o mesmo da audição, mas um outro ficcionalizado, fruto do que sua memória reteve, perdeu, modificou ou inventou. Seu personagem não nos é oferecido pronto e acabado. Seu caráter está em formação e vai sendo construído no desenrolar da peça. Sua personalidade apresenta uma natureza ambígua e múltipla, como a própria escrita de Sabina. Em sua fala, podemos perceber traços de agressividade, ressentimento e, às vezes, fragilidade. As informações que o texto fornece sobre sua personalidade são raras, não há informações sobre a sua origem. Sendo o único personagem, só conseguimos extrair alguma coisa sobre seu caráter através do que ele nos apresenta, podendo estar mentindo ou não. No monólogo, não existe a presença de um narrador capaz de preencher os vazios deixados por Félix ou de servir como mediador entre ele e o público. Da peça, que se passa num teatro, participam Félix, o diretor - Abraham Oceransky, Gustavo, Mariana e a própria Sabina. Com exceção de Félix e do diretor, que está oculto, todos os demais são personagens de bastidores, ilustrando uma espécie de prólogo da peça, não fazendo parte do restante da encenação, que se converte em um monólogo, nem da segunda versão para teatro. $O$ local da encenação não poderia ser mais propício para o desenrolar desta ação que tem como ponto principal a discussão sobre a formação teórica e prática do ator e sua postura diante dela, seu comportamento em relação a tudo que lhe é transmitido no período de seu aprendizado. Nada melhor que discutir este tema inserido no seu espaço prático e através da aplicação prática de suas teorias. Félix propõe um questionamento do teatro, para gente de teatro e utilizando uma linguagem especificamente teatral — a da representação.

Partindo dos bastidores de uma situação real para nos apresentar o contexto no qual a história de Félix se insere, Sabina Berman nos mostra não só a fragilidade, angústias e dúvidas de seu personagem principal, mas as suas próprias, enquanto aspirante a atriz. Deixa transparecer a sua ansiedade e a de seus colegas diante da possibilidade de se tornarem efetivamente atores e atrizes, para logo em seguida decepcionar-se perante o fato de não ter sido um dos alunos selecionados para submeter-se à audição. "No era de los elegidos, jamás sabré por qué."4 Ocupando a posição de es-

$\overline{4}$ BERMAN. Esta no es una obra de teatro, p.303. 
pectadora, Sabina consegue captar com sagacidade o duelo travado entre teoria e prática teatral, registrando os principais questionamentos de Félix, que poderiam também ser os seus. Se a decepção chega com o fato de não ter sido escolhida para o exame, o consolo vem rapidamente com a descoberta de seu talento para escrever. A peça que inicialmente foi escrita para ser lida, ultrapassou as próprias expectativas de Sabina, sendo adotada, várias vezes, por atores, professores e diretores. O desdobramento do monólogo, como geralmente ocorre em todas as obras, não se restringiu ao projetado pela autora. Seu monólogo, ou trechos dele, foi escolhido para ser interpretado em outras tantas audiçōes. A história de Félix passou a ser revivida por outros atores, reconstruída e reinventada por cada um em seu momento particular, quando ser Félix era interpretar a si mesmo num processo de identificação automática.

\section{O ESPAÇO}

Todo o espaço físico do teatro é explorado, ocupado em sua totalidade. A ação que se inicia nas coxias (o encontro de Sabina com o diretor) atravessa os camarins (local onde Sabina encontra objetos e figuras que a impressionam e escuta o desabafo de Mariana), passa pelos corredores (lugar onde Sabina dialoga com Gustavo e assiste à audição de Félix), concentra-se no palco (onde Félix se apresenta) e o transpõe atingindo a platéia (local onde está obscuramente instalado o diretor) para encerrarse na cabine dos técnicos, aos quais Félix solicita que retirem dele a luz, dando fim ao monólogo. Todos os elementos necessários à representação são chamados a atuar.

\section{A RESPOSTA CRITICA}

Na segunda versão do monólogo, o próprio título denuncia a quem Sabina/Félix direcionam suas críticas. O título é uma referência explícita ao manual de preparação do ator, escrito por Stanislavski e que, em espanhol, se intitula Un actor se prepara. A retirada da letra "p" traduz-se na reparação de Félix que tenta acertar as contas e testar a aplicabilidade da teoria na prática. Pode-se supor que o método da preparação do ator, utilizado por Oceransky, diretor e professor de Félix, seja proveniente do manual de Stanislavski, como demonstra a seguinte passagem do texto:

No recordaré lo que dijo Grotowsky pero si que tú dijiste que no querias volver a ver el perro que una vez me salió tan, tan, tan real, tan perro. Pobre de ti se te pones a ladrar, dijiste. ¿Pero que tienes contra mi perro, maestro? La primera vez que lo hice te encantó. e felicitaste. Bravo por ese perro dijiste. Luego, te fue cayendo mal el perro. A la quinta vez que lo hice te molestaste. Te repites dijiste. ${ }^{5}$

Stanislavski condena a repetição, assim como Oceransky a condenou em Félix, por julgá-la capaz de neutralizar toda a possibilidade de invenção criativa necessária à arte da representação.

\footnotetext{
${ }^{5}$ Berman. Esta no es una obra de teatro, p.306.
} 
Os atores da escola que estamos discutindo fazem como você fez. De início, sentem o papel, mas depois de o terem feito uma vez não continuam a senti-lo de novo, apenas recordam e repetem os movimentos, entonações e expressões exteriores que haviam elaborado de início, executando essa repetição sem emoção. (...) Acham que terão mais certeza de dar a atuação correta se se limitarem a recordar como fizeram da primeira vez que conseguiram realizá-la. ${ }^{6}$

Para proceder a análise das aproximações entre alguns aspectos da obra de Sabina Berman e a teoria de Stanislavski e fornecer subsídios para a argumentação inicial de que o monólogo de Sabina se converte em crítica das teorias assimiladas, utilizarei os elementos fornecidos pela própria peça, na seqüência em que aparecem no texto. As teorias serão enfocadas à medida que Félix vai recorrendo a elas em sua audição. Assim, iniciarei a exposiçāo pelo prólogo da peça, que subdivido em cinco pequenos episódios, ou, como denomina Stanislavski, unidades. Para o ator, estas unidades servem como elementos norteadores importantes, sinais que demarcam o caminho a seguir e o conserva na linha criadora certa. Acredito que a divisão em episódio/unidades é importante para o desenvolvimento da peça, para a própria formação teatral de Sabina e também para os que se dedicam ao estudo de sua obra. Os cinco episódios são: a apresentação do grupo de alunos feita por Sabina; o encontro involuntário de Sabina com o diretor, culminando em sua visita ao camarim; o desabafo de Mariana; o encontro de Sabina com Gustavo; e finalmente a audiçāo de Félix testemunhada por Sabina.

O grupo de alunos de teatro do qual Sabina fazia parte se desintegrou após um longo período de aprendizagem, que para muitos foi excessivo. Os motivos foram variados, indo da simples impaciência com a demora do curso e de uma possível apresentação, a descoberta da inutilidade do teatro até chegar à constatação de uma falta de vocação. Mariana e Gustavo, além de Félix, foram os alunos escolhidos para prestarem o exame de audição. Através do relato de Gustavo, sabemos que Mariana não suportou a pressão da prova, o que transformou sua primeira tentativa em um desastre. No palco, Mariana comportou-se de forma semelhante à personagem de Stanislavski, Sônia Veliaminova, namorando a platéia, não interpretando o papel que lhe fora destinado, preferindo mostrar "toda a sua pessoa, porque no palco ficava melhor exposta". 'Assim como Sônia, Mariana nāo atuou e se restringiu a tentar conquistar a platéia pela sua beleza e simpatia. Para piorar ainda mais o estado de nervosismo de Mariana, Gustavo presenciou a cena e pôs-se a rir da colega, sendo advertido por Oceransky, assim como Stanislavski havia advertido os colegas de Maria, outra personagem de seu livro que se submeteu a uma audição: "Meus amigos, vocês estão numa sala de aulas. E Maria está atravessando um momento importantíssimo de sua vida de artista. Procurem aprender quando se deve rir e do quê." A audição de Gustavo não é mostrada na peça. Ele aparece como um narrador da audição de Mariana e, ao ser interrogado por Sabina, confirma a presença de Félix no palco, suscitando a curiosidade da mesma que se dirige às coxias para observar o que acontecia, dando início ao monólogo.

\footnotetext{
${ }^{6}$ STANISLAVSKI. A preparação do ator, p.49.

${ }^{7}$ IBIDEM. p.58.

${ }^{8}$ BeRman. Esta no es una obra de teatro, p.305.
} 
No teatro onde se realiza a audição de Félix estava sendo encenada a peça O bosque russo. O diretor, Abraham Oceransky, aproveita o cenário já existente, composto por cilindros que simulam troncos de árvores, para realizar a audiçāo de seus alunos. Tudo indica que o texto a ser encenado era extraído desta peça. Félix também se encontra neste bosque fictício. Dos bastidores, Sabina e Gustavo assistem à audição do colega. "Por encima de su hombro ví, en el escenario, a Félix. Estaba en el centro de la obscuridad, de cuclillas bajo el círculo de luz que habría de seguirlo hasta el final de su monólogo. Nadie, ni siquiera Gustavo, hubiera tenido las agallas para interrumpir tanta emoción." 9

Partindo da descrição do cenário apresentada por Sabina, podemos perceber a presença de um elemento importante, não só no desenrolar da peça, mas na própria teoria de Stanislavski, quando este prepara seus alunos, futuros atores e atrizes, para a encenação, e que ele denomina como Círculo de atenção. O espaço iluminado no palco, e em alguns momentos fora dele, consiste num círculo projetado pelo refletor e que incide sobre alguém ou algo que está sob o foco de luz, atribuindo-lhe importância maior em relação às outras coisas presentes, diferenciando-o. Félix encontra-se no centro do palco, sob o foco de luz, ao seu redor tudo foi tragado pela escuridão. Nesta situação, que se prolongará até o fim da audição, seu estado se transforma no que Stanislavski chamou de solidão em público. "Você está em público porque nós todos estamos aqui. É solidão porque você está separado de nós pelo pequeno círculo de atenção. Durante uma atuação com uma platéia de milhares de pessoas, poderá sempre encerrar-se dentro deste círculo, como um caracol em sua casca." ${ }^{10}$ Porém esta hipotética esperança de refúgio no círculo de luz é traduzida para Félix como uma prisão, que, ao invés de protegê-lo, o expõe de forma ininterrupta e violenta. Félix encerra-se nesse suposto caracol tempo suficiente para transmitir ao público, oculto pela escuridão, toda a carga emocional de seu texto interior, contaminando-nos como fez com Sabina. No entanto, quando se sente por demais exausto e incomodado com a ausência de respostas e com sua solidão, manifesta o desejo de fugir daquela situação e pede a liberdade da escuridão que o igualaria aos que estão protegidos pelo anonimato e pela falta de luz. A luz se converte no signo semiótico por excelência deste monólogo, pois permite ao personagem ir do brilho das luzes da ribalta, ocupando o centro da atenção, aprisiona-o durante toda a exposição, para só libertá-lo mediante um pedido que é praticamente uma ordem: "Bueno, entonces quítame esta luz de encima." A luz dialoga com Félix, transformando-se em sua companheira e também algoz, perseguindo-o em todos os cantos, revelando-se uma verdadeira coadjuvante de toda a trama.

No momento em que Sabina e Gustavo avistam o palco, Félix está travando um duelo interno com sua memória, pois não consegue se lembrar de nada do que aprendeu com as teorias de Stanislavski, Grotowsky ou Artaud, e nenhum deles pode ajudálo agora. Félix só consegue se lembrar de que é necessário revisar seus textos e fica repetindo esta frase, insistentemente: revisa teus textos. Recorda que está no palco e

\footnotetext{
${ }^{9}$ BERMAN. Esta no es una obra de teatro, p. 305.

${ }^{10}$ StanisLavski. A preparaçāo do ator, p.109.

"Berman. Esta no es una obra de teatro, p.311.
} 
que estando ali tem de atuar, não podendo ficar parado sem executar nenhuma ação. Precisa convencer a platéia e a si mesmo que está num bosque russo. Não consegue. Lembra-se de que o mestre está em alguma parte da escuridão, observando-o silenciosamente, e isto o deixa ainda mais ansioso. A escuridão na qual se encontra o mestre é bem mais confortável e inspiradora que a solidão brilhante que enfrenta no palco. A escuridāo e a luz travam também seu conflito particular.

Félix acusa o diretor Oceransky de tê-lo ensinado apenas três técnicas de concentração, as mesmas constantes no manual de Stanislavski, e que destas, apenas uma funcionava. "Aquella de sentarse en el piso com las piernas cruzadas y mirar un punto fijamente hasta que zaz: en mi mente se abria un silencio, se borraba toda intención, y entonces tú ordenabas..."12 Assim como o personagem Kóstia, de Stanislavski, Félix solicita ao diretor que lhe ordene que faça algo, como na época de estudante, porém o mestre permanece calado e impassível, aguardando que Félix tome sua própria decisão de atuar. Para Stanislavski, se o ator não sente em seu íntimo a vontade de executar algo, se em seu interior não se acende uma centelha que o motive à ação, ele não pode ser um verdadeiro ator. Como se tivesse relembrado as teorias aprendidas, Félix começa a interpretar, não um personagem do bosque russo, mas a sua melhor interpretação dos tempos de estudante. Félix fica repetindo a atuação e não faz uma releitura e nem cria algo novo. Através da repetição de Félix, Sabina tenta mostrar a seus leitores/espectadores que não é só a repetição de um personagem que leva à estagnação, mas também a repetição de teorias sem uma reflexão que justifique e sustente a sua utilidade. Assim, a ausência de uma reflexão crítica, bem fundamentada, pode levar até mesmo o mais brilhante executor de uma ação à ignorância absoluta, transformando-o em marionete.

Félix tem paixão pelo teatro e está enfeitiçado pelos seus encantos. No teatro, o ator pode se tornar um escravo ou um deus, experimentando sentimentos e situações contraditórias. Pode ser homem, mulher, criança, velho, sem que para isso tenha que sofrer as ações do tempo. Para Grotowsky, o ator pode se tornar um santo, quando preparado adequadamente. Félix nāo se sente um santo, ao contrário, sozinho no palco, abandonado à própria sorte, sente-se o mais miserável dos homens. Não há vontade em suas atitudes, apenas resignação. Foi transformado num trapo humano que incursiona pelo seu subconsciente. Suas opiniões são expressadas de forma frágil e não são levadas a sério. Submete-se às ordens do mestre e das teorias massacrantes, aparentemente, sem contestá-las. Mas sabemos que seu desabafo é prova viva de sua vontade e coragem. O que aparenta ser uma não ação, naquele momento, se transforma num instrumento de luta.

¿Me das permiso de ser un santo, maestro? Desconfio de los santos, iSabes nunca les he creido que puedan amar sin pedir nada a cambio? Pero si tú me ordenas que sea un santo, okey dokey, voy cederle mi corazón y mi cerebro a la santidad. Ordéname ser un santo, maestro. Ordéname ser Hitler. Ordéname ser un oso, un perro. Elige tú lo que debo ser. Yo no quiero la responsabilidad. Ordéname ser un santo. Ordénamelo. ${ }^{13}$

\footnotetext{
12 Berman. Esta no es una obra de teatro, p.306.

${ }^{13}$ IBIDEM. p. 310.
} 
O diretor nada responde. Diante desta ausência de resposta, Félix mata o diretor, não só a ele, mas a todos os teóricos. A interlocução com este outro ausente se torna psicologicamente insustentável para ele, que sente a necessidade de ser guiado e de receber todas as dádivas prometidas a quem seguisse as teorias. Félix necessita de alguém que lhe ensine as regras do jogo teatral, que lhe aponte os erros e o parabenize pelos acertos, que lhe mostre como é ou como deve ser as coisas. Félix é humano e necessita que o diretor viva, mesmo não crendo mais nele. Félix sente a necessidade de resgatar o sentido de sua arte, de sua profissão, de sua vida. O teatro é pautado pela comunicação e se ela não existe, não há teatro. Se o diretor morre, para quem Félix vai dedicar sua atuação? Félix sente a necessidade de resgatar o sentido de sua arte, de sua profissão, de sua vida. Ainda que se elimine todos os demais elementos do teatro, como deseja Grotowsky, a existência de uma relação de reciprocidade entre ator e platéia é fundamental para que a ação dramática tenha lugar. Assim, Félix precisa da avaliaçāo e dos ensinamentos do único elemento que está presente, ainda que na obscuridade, para que possa sobreviver, para que reencontre o seu equilíbrio e não enlouqueça. Se a comunicação entre as partes não acontece, a ação dramática tem seu fim. "Bueno, entonces quítame esta luz de encima", para que eu não seja sugado pela iluminação solitária e possa desfrutar da escuridão solidária.

Embora esteja tratando de uma caso particular, Sabina transpõe os limites da fronteira mexicana e discute os problemas da identidade, de heteroglossia, direcionando tais discussões para todos os candidatos a atores/atrizes latino-americanos.

¿Como voy a ser actor si el teatro lo inventaron del outro lado del mundo? Toda la teoria que me enseñaste es falsa, maestro.(...) Por supuesto: Voy a aprender ruso y ya. Ahora vuelvo. Aprendo ruso, entiendo lo que significa dubne, me tomo un vodka de verdad vodka y vuelvo. Com dubne vas a ver cómo te actúo cualquier papel. ${ }^{14}$

Este trecho do monólogo, resume, de maneira bastante magistral, o questionamento que norteou todo este trabalho. De que valem as teorias importadas num contexto político, econômico e social completamente diverso? Quebrando a barreira da língua se quebra a barreira da cultura, que é muito maior? Félix banaliza a diferença e a reduz a uma barreira meramente lingüística. Porém, no seu íntimo, sabe que a barreira lingüística não impede a comunicação e a mudança, mas as barreiras invisíveis e/ou visíveis do choque entre as sociedades nas esferas cultural, política, social e econômica, criam obstáculos intransponíveis, que são reforçados cotidianamente pelos discursos de quem está no poder.

Félix sabe que é necessário tomar uma decisão e faz uma nova tentativa. Está nervoso. Sabe que deve atuar independente das circunstâncias, mas falta-lhe a intenção e os objetivos que o motive a cumprir bem o papel. "No sé como hacerlo bien pero cuando lo hago mal si sé." ${ }^{15}$ Invoca novamente a presença dos teóricos numa tentativa frustrada de escapar de sua prática particular e adotar qualquer das teorias importadas, num processo de repetição e imitação.

\footnotetext{
${ }^{14}$ Berman. Esta no es una obra de teatro, p.307.

${ }^{15}$ IBIDEM. p. 308.
} 
Grotowsky, iestás ahí? Stanislavsky. Gorki. Tolstoi. iDostoyevsky! Entonces por favor Lenin. No importa si son autores teatrales, con tal que sean rusos. Vete maestro. A ti no te llamé. Tú no eres ruso. Tu apellido es ruso pero tú naciste ya de este lado del mundo. No insistas, no te escucho. (...) Ya no creo en nada que haya salido por tus labios. ¿Cuánto de lo que me dijiste me sirve ahora? Te sigo llamando maestro por pura cortesia. Por pura cortesia a los rusos. No quiero blasfemar diciendo tu apellido ruso. iSabes tú lo que significa "dubne"? Qué derecho tienes de considerarte maestro de teatro si no sabes lo que significa "dubne". 16

Com este discurso, que beira a comicidade, Sabina mostra a resignação de Félix. Porém a atitude dele não é irrefletida, mas ao contrário, através do reducionismo que ele faz das teorias teatrais importadas e dos autores e diretores que a ela se dedicam ou dedicaram, Sabina realiza uma desconstrução do cânone, buscando resgatar as raízes do teatro latino-americano, numa tentativa de construir as próprias práticas e teorias. Seu monólogo poderia ser interpretado como uma denúncia da necessidade de se criar uma escrita, uma direção e um ensino de teatro latino-americanos voltado para as tradições e costumes deste povo.

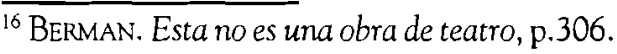




\section{A B STRACT}

This article objectives to analyse the conflicts between theory and pratical theatre using two monologues of mexican drama by Sabina Berman and the guide to actor preparation by Stanislavsky, trying to keep the existing dialogue in both.

\section{KEY WORDS}

theatrical theory, Sabina Berman, Stanislavski

\section{REFERÊNCIAS BIBLIOGRÁFICAS}

Barba, Eugenio, Savarese, Nicola. A arte secreta do ator. Dicionário de Antropologia Teatral. Campinas: Ed. da Unicamp, 1995.

Berman, Sabina. Esta no es una obra de teatro. In: Teatro de Sabina Berman. México: Editora Mexicanos Unidos, 1985.

Berman, Sabina. Un actor se repara. In: Teatro de Sabina Berman. México: Editora Mexicanos Unidos, 1985.

Berman, Sabina. Yakee. In.: Teatro de Sabina Berman. México: Editora Mexicanos Unidos, 1985.

Demarinis, Marco. Compreender el teatro. Buenos Aires: Galerna, 1997.

Grotowski, Jerzy. Em busca de um teatro pobre. 4. ed. Trad. Aldomar Conrado. Rio de Janeiro: Civilização Brasileira, 1992.

Guinsburg, J. (org.) Semiologia do Teatro. São Paulo: Perspectiva, 1988.

Helbo, André (org.) Semiologia da representação: teatro, televisão, história em quadrinhos. Trad. Eduardo Peñuela Canizal et ali. São Paulo: Cutrix, 1980.

Pallotini, Renata. Dramaturgia. A construção do personagem. São Paulo: Ática, 1989.

Ryngaert, Jean Pierre. Introdução à analise do teatro. Trad. Paulo Neves. São Paulo: Martins Fontes, 1996.

Stanislavski, Constantin. A preparaçāo do ator. 3. ed. Trad. Pontes de Paula Lima, Rio de Janeiro: Civilização Brasileira, 1976.

Ubersfeld, Anne. Semiótica Teatral. Murcia: Cátedra, 1989. 